\title{
HUBUNGAN PERTUKARAN PEMIMPIN-ANGGOTA DENGAN KEPUASAN KERJA DAN KOMITMEN ORGANISASIONAL YANG DIMEDIASI OLEH KEADILAN ORGANISASIONAL
}

\author{
Vibriwati \\ Universitas Pembangunan Nasional "Veteran" Yogyakarta
}

\begin{abstract}
This research was developed and conducted to test a model for examining the influence of leader-member exchange (LMX) on job satisfaction, organizational commitment and organizational justice that was used as mediating variables. The subjects of the research was one hundred and seventy nine employees in four oil companies. The application of structural equation modelling on the predicted model showed that leader-member exchange (LMX) affected job satisfaction and organizational commitment through its effects on organizational justice.

Keywords: LMX, organizational justice, job satisfaction, organizational commitment.
\end{abstract}

\section{PENDAHULUAN}

Pendekatan baru mengenai studi kepemimpinan di dalam perusahaan telah dikembangkan dan diteliti oleh Graen dan koleganya. Pendekatan yang pada awalnya disebut teori Vertical Dyad Linkage (VDL) kemudian lebih dikenal sebagai Leader-Member Exchange (LMX) atau pertukaran pemimpin-anggota (Dienech dan Liden, 1986). Dasar pemikiran teori LMX adalah bahwa di dalam unit kerja, supervisor mengembangkan tipe hubungan yang berbeda dengan bawahannya (Erdogan et al., 2002).

LMX menyediakan cara yang berguna untuk mengkonseptualisasikan hubungan antara pemimpin dan persepsi bawahan terhadap keadilan. Tyler mengatakan bahwa meningkatnya kesempatan untuk mengekspresikan opini ditunjukkan dengan mempertinggi persepsi keadilan bawahan dan evaluasi bawahan terhadap kemampuan kepemimpinan atasan, khususnya ketika bawahan memiliki pengendalian keputusan yang rendah (Pillai et al., 1999). Beberapa penelitian menunjukkan adanya hubungan antara LMX dengan keadilan organisasional (Manogran et al., 1994; Pillai et al.,1999; dan Wayne et al., 2002), namun hasil penelitian-penelitian tersebut masih menimbulkan minat untuk menelitinya. Hal ini disebabkan oleh ketidakpastian hubungan antara LMX dan keadilan organisasional yang dilaporkan merefleksikan keadilan organisasi merupakan outcome proses LMX atau merupakan elemen dalam pengembangan hubungan LMX (Scandura, 1999). Hal tersebut ditunjukkan oleh adanya perbedaan pola hubungan dalam penelitian Manogran et al. (1994) dan Wayne et al. (2002) dengan penelitian Pillai et al. (1999).

Penelitian Manogran et al. (1994) menunjukkan bahwa persepsi karyawan terhadap keadilan organisasionallah merupakan dasar hubungan LMX. Penelitian Wayne et al. (2002), meskipun hasilnya tidak didukung, menunjukkan bahwa keadilan organisasional diprediksi mempengaruhi LMX, dan dikatakan bahwa satu aspek dari perlakuan yang mungkin relevan dengan LMX adalah keadilan organisasional. Kedua penelitian di atas menunjukkan bahwa keadilan organisasional memiliki implikasi pada hubungan LMX (Scandura, 1999). Penelitian Pillai et al. (1999) menunjukkan bahwa keadilan organisasional merupakan outcome LMX. Kualitas LMX 
akan mempengaruhi persepsi bawahan terhadap keadilan di dalam organisasi. Semakin tinggi kualitas LMX semakin tinggi pula persepsi bawahan terhadap keadilan di tempat kerjanya.

Beberapa penelitian menunjukkan adanya hubungan langsung antara LMX dengan kepuasan kerja (Pillai et al., 1999; Sherony dan Green, 2002; Manogran et al., 1994; Erdogan et al., 2002) maupun LMX dengan komitmen organisasional (Manogran et al., 1994; Erdogen et al., 2002). Penelitian terdahulu juga menemukan adanya hubungan tidak langsung antara LMX dengan kepuasan kerja, yang dimediasi oleh keadilan organisasional. Model yang dikembangkan Pillai et al. (1999) menunjukkan LMX berhubungan dengan kepuasan kerja melalui keadilan organisasional. Namun penelitian tersebut belum memasukkan komitmen organisasional sebagai outcome LMX yang dimediasi keadilan organisasional. Berdasarkan hal itu, maka penelitian ini mencoba mengembangkan dan menguji model hubungan pertukaran pemimpin-anggota (LMX) dengan kepuasan kerja dan komitmen organisasional yang dimediasi oleh keadilan organisasional.

\section{TINJAUAN LITERATUR DAN PENGEMBANGAN HIPOTESIS}

Graen mendefinisikan LMX sebagai kualitas hubungan pertukaran interpersonal antara pekerja dan supervisornya. Dasar pemikiran teori LMX adalah bahwa di dalam unit kerja, supervisor mengembangkan tipe hubungan yang berbeda dengan bawahannya (Erdogan et al., 2002). Konsekuensinya, atasan dengan sepuluh bawahan akan memiliki sepuluh hubungan LMX yang berbeda (Bauer dan Green, 1996).

Kualitas hubungan menentukan jumlah usaha fisik maupun mental, sumberdaya material, informasi dan dukungan sosial yang dipertukarkan antara supervisor dan bawahannya (Liden et al., 1993 dalam Erdogen et al., 2002). Hubungan akan berkembang di dalam pertukaran kualitas tinggi yang diwujudkan dengan tingkat saling percaya dan hormat yang tinggi, dan kualitas rendah didasarkan pada kontrak kerja formal. Dansereau et al. (dalam Scandura, 1999) mempresentasikan sebuah model deskriptif bagaimana kelompok kerja dibedakan menjadi ingroup dan out-group didasarkan pada kualitas hubungan pemimpin-anggota yang muncul antara supervisor dan anggotanya di dalam kelompok kerja Anggota in-group dikarakteristikkan oleh kepercayaan, interaksi, dukungan dan reward formal/informal yang tinggi. Anggota out-group dikarakteristikkan oleh kepercayaan, interaksi, dukungan dan reward formal/informal yang rendah (Dienesch dan Liden, 1986).

Model pengembangan LMX menyatakan bahwa pembedaan kelompok kerja menjadi ingroup dan out-group memiliki implikasi bagi munculnya keadilan organisasional (Scandura, 1999). Menurut Kabanoff dan Meindl, ide bahwa beberapa bawahan diperlakukan lebih baik daripada yang lain adalah inkonsisten dengan norma equality. Graen dan Uhl-Bien menyatakan bahwa riset empiris yang mempelajari terus menerus telah mendokumentasikan perbedaan dalam kualitas hubungan, dan hasilnya lebih menguntungkan anggota in-group. Hasil tersebut relevan dengan konsep keadilan organisasional karena anggota out-group mungkin melihat pemimpin mereka memperlakukan mereka dengan tidak adil (Scandura, 1999).

Keadilan organisasional menggambarkan persepsi keadilan individu (atau kelompok) terhadap perlakuan yang diterima dari organisasi dan reaksi keperilakuan mereka terhadap persepsi tersebut (James, 1993 dalam Lam et al., 2002). Konseptualisasi dua dimensional keadilan yang secara luas masih diadopsi literatur, yaitu keadilan distributif yang berkenaan dengan keadilan persepsian pada outcome yang diterima karyawan dan keadilan prosedural yang menggambarkan keadilan persepsian pada prosedur yang digunakan untuk menentukan outcome tersebut (Lam et al., 2002).

Hubungan LMX kualitas tinggi (in-group) merupakan bukti keberhasilan pengembangan kepercayaan yang terus menerus antara pemimpin dan anggota. Kualitas LMX yang dibangun tersebut akan mempengaruhi persepsi anggota pada keadilan di dalam organisasi. Anggota ingroup memandang tempat kerja lebih adil daripada anggota out-group. Didukung oleh penelitian 
Pillai et al. (1999) yang menunjukkan bahwa terdapat hubungan positif antara LMX dengan keadilan distributif dan keadilan prosedural, maka hipotesis yang dikembangkan:

H1a: LMX berpengaruh positif terhadap keadilan distributif.

H1b: LMX berpengaruh positif terhadap keadilan prosedural.

Sikap yang merupakan reaksi karyawan terhadap perlakuan organisasi diantaranya ditunjukkan dalam bentuk kepuasan kerja dan komitmen organisasional. Sebagai suatu sikap, konsep komitmen organisasional berbeda dengan kepuasan kerja. Komitmen dipandang lebih global, yang merupakan perefleksian respon afektif umum pada organisasi, sedangkan kepuasan kerja lebih menekankan pada lingkungan tugas yang lebih spesifik yang mana karyawan melakukan tanggung jawabnya (Lum et al., 1998). Komitmen afektif sebagai proses attitudinal melihat orang berfikir mengenai hubungan mereka dengan organisasi dalam hal value dan goal congruency. Tingkat individual's goals dan value menyatu dengan organisasi dihipotesiskan mempengaruhi secara langsung hasrat individu untuk tetap berada di organisasi. Karyawan dengan komitmen afektif yang kuat akan tetap berada di dalam organisasi karena menginginkannya.

Beberapa akademisi berargumentasi bahwa keadilan distributif berpengaruh lebih spesifik yaitu pada person-referenced outcome seperti kepuasan dengan kenaikan gaji atau evaluasi kinerja. Sedangkan Keadilan prosedural berpengaruh lebih spesifik pada evaluasi sistem dan kekuasaan yang lebih umum (Greenberg, 1990b; serta Lind dan Tyler, 1988 dalam Colquitt, 2001). Konsisten dengan prediksi tersebut, McFarlin dan Sweeney (1992), dalam Colquitt (2001) menemukan bahwa keadilan distributif adalah prediktor yang lebih baik two "personal outcomes" (kepuasan pembayaran dan kepuasan kerja), dan keadilan prosedural menjadi prediktor yang lebih baik pada two "organizational outcomes" (komitmen organisasional dan evaluasi bawahan terhadap atasan). Didukung oleh beberapa penelitian yang menunjukkan adanya hubungan positif antara keadilan organisasional dan kepuasan kerja (Pillai et al, 1999; Manogran et al, 1994; dan Colquitt, 2001), dan beberapa penelitian yang menemukan hubungan positif antara keadilan prosedural dan komitmen organisasional (Manogran et al., 1994), maka hipotesis yang dikembangkan:

$\mathrm{H} 2$ : Keadilan distributif berpengaruh positif terhadap kepuasan kerja.

H3: Keadilan prosedural berpengaruh positif terhadap komitmen organisasional.

Teori LMX mengkonseptualisasikan kepemimpinan sebagai sebuah proses yang dipusatkan pada interaksi antara pemimpin dan anggotanya. Yukl (1998, dalam Dionne, 2000) menyatakan bahwa LMX menggambarkan bagaimana seorang pemimpin dan anggota secara individual mengembangkan sebuah hubungan seperti mereka saling mempengaruhi dan merundingkan peran bawahan dalam organisasi. Ketika hubungan berkembang, ruang gerak yang diberikan supervisor pada bawahan akan meningkat. Sebagai konsekuensinya LMX secara positif berhubungan dengan sikap-sikap yang menguntungkan seperti kepuasan kerja dan komitmen organisasional. Didukung oleh penelitian Pillai et al. (1999), Sherony dan Green (2002), Manogran et al. (1994), dan Erdogan et al. (2002) yang menyatakan LMX mempengaruhi kepuasan kerja, serta penelitian Manogran et al. (1994) dan Erdogan et al. (2002) yang menyatakan LMX mempengaruhi komitmen organisasional, maka hipotesis yang dikembangkan:

H4a: LMX berpengaruh positif terhadap kepuasan kerja.

H4b: LMX berpengaruh positif terhadap komitmen organisasional.

Ketika kualitas LMX tidak berhubungan secara langsung dengan kepuasan kerja, maka diprediksikan hubungan secara tidak langsung melalui keadilan distributif. Ketika kualitas LMX tidak berhubungan secara langsung dengan komitmen organisasional, maka diprediksikan hubungan secara tidak langsung melalui keadilan prosedural. Didukung oleh penelitian Pillai et al. (1999), maka hipotesis yang dikembangkan:

H5a: Keadilan distributif memediasi hubungan LMX dengan kepuasan kerja.

$\mathrm{H} 5 \mathrm{~b}$ : Keadilan prosedural memediasi hubungan LMX dengan komitmen organisasional. 
$\mathrm{H} 5 \mathrm{a}(+)$

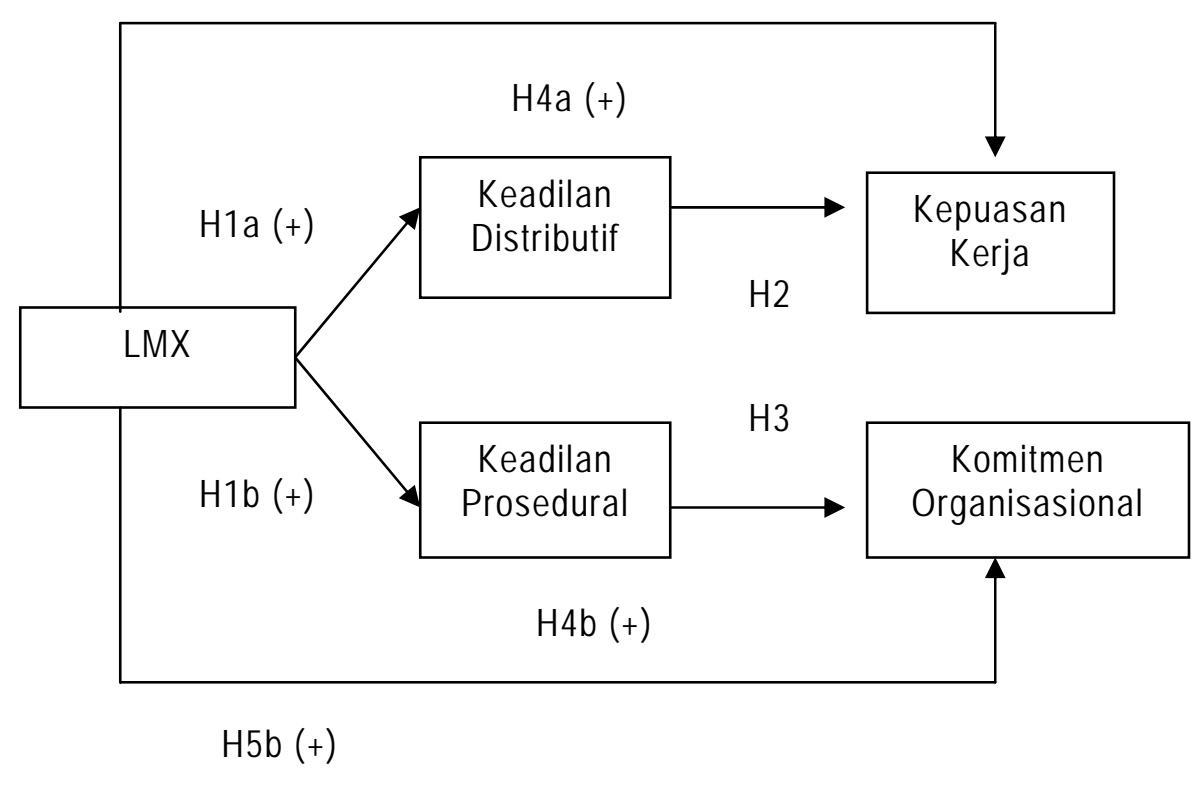

Gambar 1

Model Penelitian:

Model Konseptual Untuk Menguji Hubungan Variabel Penelitian

\section{PEMILIHAN SAMPEL DAN METODA PENGUMPULAN DATA}

Sampel diambil dari empat perusahaan minyak yang ada di Indonesia yang memiliki kategori sebagai perusahaan swasta. Tehnik pengambilan sampel adalah nonprobability sampling khususnya convenience sampling. Total kuesioner yang terdistribusi sebanyak 250 dan kembali sejumlah 181 atau dengan response rate 72 \%. Terdapat 2 kuesioner yang tidak dapat digunakan karena data yang tidak lengkap, sehingga jumlah sampel yang dapat digunakan untuk analisis data sebanyak 179 .

Metoda pengumpulan data yang digunakan yaitu survei dengan menggunakan kuesioner yang diberikan dan diisi sendiri oleh responden. Kuesioner diberikan kepada responden melalui pos maupun e-mail. Kuesioner penelitian terdiri dari satu bagian (single survey instruments) yang berisi daftar pertanyaan mengenai identitas responden dan variabel penelitian yang terdiri dari LMX, keadilan distributif, keadilan prosedural, kepuasan kerja dan komitmen organisasional .

\subsection{Pengukuran Variabel}

Penelitian ini menggunakan tujuh item untuk mengukur kualitas LMX yang dilihat dari perspektif bawahan diadaptasi dari Scandura dan Graen (1984) dan memiliki reliabilitas sebesar 0,782 . Pengukuran menggunakan skala respon lima poin dari $1=$ sangat tidak setuju sampai 5 = sangat setuju.

Keadilan distributif diukur dengan menggunakan 5 item diadaptasi dari Moorman (1991) yang juga digunakan oleh Niehoff dan Moorman (1993) dan memiliki reliabilitas 0,850. Pengukuran dengan menggunakan skala respon lima poin dari $1=$ sangat tidak setuju sampai $5=$ sangat setuju.

Keadilan prosedural diukur dengan menggunakan 6 item yang diadaptasi dari Moorman (1991) yang juga digunakan oleh Niehoff dan Moorman (1993) dan memiliki reliabilitas 0,789. 
Pengukuran menggunakan skala respon lima poin dari $1=$ sangat tidak setuju sampai $5=$ sangat setuju.

Kepuasan kerja diukur dengan menggunakan 20 item pernyataan pendek dari Minnesota Satisfaction Questionaire (MSQ) yang diadaptasi dari Weiss (1967) dalam Manogran et al. (1994) dan memiliki reliabilitas sebesar 0,899 . Pengukuran menggunakan skala respon lima poin dari $1=$ sangat tidak puas sampai 5 = sangat puas.

Komitmen organisasional diukur menggunakan 8 item yang dikembangkan oleh Allen dan Meyer (1990) dalam Dunham et al. (1994) merupakan indikator dari komitmen afektif dan memiliki realibilitas 0,833 . Pengukuran menggunakan skala respon lima poin dari $1=$ sangat tidak setuju sampai 5 = sangat setuju.

\subsection{Tehnik Analisis Data}

Untuk menguji hubungan yang diusulkan digunakan structural equation modeling (SEM). SEM adalah tehnik multivariat yang mengkombinasikan aspek-aspek multiple regression dan factor analysis untuk mengestimasi serangkaian hubungan saling ketergantungan secara simultan (Hair et al., 1998).

Kriteria pengujian goodness-of-fit untuk mendukung suatu model sebagai berikut: $X^{2}$ - Chisquare untuk menguji kesesuaian model secara keseluruhan dengan data. Model dikatakan baik jika chi-square-nya rendah. The Root Mean Square of Approximation (RMSEA) untuk mengkompensasi chi-square sampel besar. Nilai kritisnya $<=0,08$. Goodness-of-Fit Index (GFI) untuk mengidentifikasi tingkat kesesuaian model secara keseluruhan dengan model yang diprediksi untuk dibandingkan dengan data hasil observasi. Nilai kritisnya $>=0,90$. Adjusted GFI (AGFI) adalah pengembangan GFI. Nilai kritisnya $>=0,90$. Normed chi square (CMIN/DF) adalah ukuran yang diperoleh dari chi square yang dibagi dengan degree of freedom. Nilai kritisnya $<=2$. Tucker-Lewis Index (TLI) untuk membandingkan sebuah model yang diuji dengan null model. Nilai kritisnya $>=0,95$. Comparative Fit Index (CFI) untuk menguji kesesuaian model yang tidak dipengaruhi oleh jumlah sampel. Nilai kritisnya $>=0,94$.

\section{ANALISIS HASIL DAN PEMBAHASAN}

\subsection{Statistik Deskriptif dan Korelasi}

Tabel 1 menunjukkan hasil statistik deskriptif yang terdiri dari nilai minimum, nilai maksimum, nilai rata-rata (mean) dan standar deviasi dari setiap variabel, dan hasil analisis korelasi yang menunjukkan bahwa semua variabel memiliki korelasi yang signifikan pada level 0,01 .

Tabel 1

Statistik Deskriptif dan Korelasi antar Variabel Penelitian

\begin{tabular}{lccccccccc}
\hline Variabel & Min Max & Mean & SD & $\mathbf{1}$ & $\mathbf{2}$ & $\mathbf{3}$ & $\mathbf{4}$ & $\mathbf{5}$ \\
\hline LMX & 15 & 35 & 24,05 & 3,84 & 1,00 & & & & \\
KD & 10 & 25 & 16,72 & 3,27 & $0,28^{\star *}$ & 1,00 & & & \\
KP & 8 & 25 & 17,45 & 3,08 & $0,47^{* *}$ & $0,29^{* *}$ & 1,00 & & \\
KK & 22 & 64 & 46,01 & 7,21 & $0,42^{* *}$ & $0,47^{* *}$ & $0,41^{* *}$ & 1,00 & \\
KO & 9 & 31 & 22,44 & 4,33 & $0,22^{* *}$ & $0,31^{* *}$ & $0,24^{* *}$ & $0,39^{* *}$ & 1,00 \\
\hline
\end{tabular}

**Signifikan pada level 0,01 (2-tailed)

Sumber: Data primer diolah 


\subsection{Hasil Uji Model Struktural}

Tabel 2

Hasil Uji Goodness-of-fit Model Penelitian

\begin{tabular}{lcc}
\hline Goodness-of-fit indices & Nilai Kritis & Hasil Model \\
\hline X2 - Chi-Square & & \\
Derajat bebas, df & & 36,895 \\
X$^{2}$-Significant Probability & $>=0,05$ & 4 \\
Relative X² (Cmin/DF) & $<=2,00$ & 0,000 \\
GFI & $>=0,90$ & 9,224 \\
AGFI & $>=0,90$ & 0,930 \\
TLI & $>=0,95$ & 0,739 \\
CFI & $>=0,94$ & 0,505 \\
RMSEA & $<=0,08$ & 0,802 \\
& & 0,215 \\
\hline
\end{tabular}

Sumber: Data primer diolah

Pada tabel 2 terlihat hanya GFI yang menunjukkan nilai yang lebih besar daripada nilai kritisnya, sehingga dikatakan model penelitian belum maksimal fit dengan data. Oleh karena itu diperlukan model alternatif yang dapat lebih merepresentasikan data penelitian.

\subsection{Evaluasi Hubungan kausalitas dan Hasil Pengujian Hipotesis}

Hubungan kausalitas dikatakan signifikan apabila hubungan antara kedua variabel memiliki critical ratio (CR) lebih besar dari 2. Koefisien jalur (standardized regression) antar variabel dan signifikansinya dapat dilihat pada tabel 3.

Tabel 3

\section{Hubungan Kausalitas dan Hasil Uji Hipotesis}

\begin{tabular}{|c|c|c|c|c|}
\hline \multicolumn{2}{|r|}{ Jalur } & Koefisien Jalur & CR & Keterangan \\
\hline KD & LMX & 0,284 & 3,953 & Signifikan \\
\hline KP & LMX & 0,471 & 7,121 & Signifikan \\
\hline KK & KD & 0,382 & 5,885 & Signifikan \\
\hline KO & ..... KP & 0,175 & 2,139 & Signifikan \\
\hline KK & LMX & 0,312 & 4,812 & Signifikan \\
\hline $\mathrm{KO}$ & LMX & 0,139 & 1,703 & Tidak Signifikan \\
\hline
\end{tabular}

Sumber: Data primer diolah

Pada tabel 3 dapat dilihat hasil pengujian hipotesis secara parsial. Didasarkan pada CR maka $\mathrm{H} 1 \mathrm{a}, \mathrm{H} 1 \mathrm{~b}, \mathrm{H} 2, \mathrm{H} 3$ dan $\mathrm{H} 4 \mathrm{a}$ didukung, sedangkan $\mathrm{H} 4 \mathrm{~b}$ tidak didukung. Pada tabel 3 belum terlihat hasil pengujian hipotesis variabel mediasi. Pengujian hipotesis variabel mediasi dilakukan dengan mencari perbedaan chi-square dan degree of freedom (df) atau chi-square test dari model yang memiliki konstruk dan indikator yang sama namun memiliki jalur yang berbeda. Apabila selisih chisquare dan degree of freedom signifikan maka pengaruh mediasi dikatakan signifikan (Lee, 2000). 
Chi-square model penelitian 36,895 pada df 4, sedangkan chi-square model tanpa efek mediasi 96,484 pada df 6 . Perbedaan chi-square dan df kedua model tersebut adalah 59,58 pada df 2 (signifikan $p=0,001$ ). Perbedaan yang signifikan dari kedua model tersebut mengindikasikan adanya pengaruh mediasi yang signifikan. Dengan demikian $\mathrm{H} 5 \mathrm{a}$ dan $\mathrm{H} 5 \mathrm{~b}$ didukung.

\subsection{Alternatif Model}

Model alternatif yang diajukan adalah dengan menambah jalur dari kepuasan kerja ke komitmen organisasional. Hubungan kepuasan kerja dan komitmen organisasional memiliki justifikasi teori yang kuat dan didukung oleh beberapa hasil penelitian empiris yang menyatakan bahwa kepuasan kerja berpengaruh positif terhadap komitmen organisasional diantaranya penelitian Clugston (2000), Lum et al. (1998), dan Testa (2001).

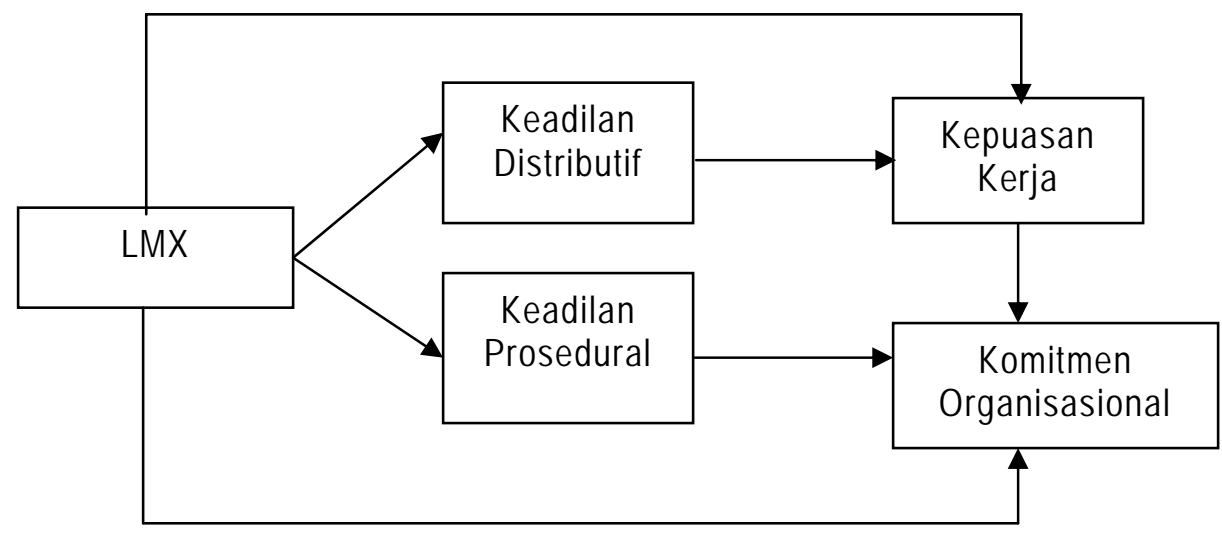

Gambar 2

Model Alternatif

Perbandingan hasil goodness-of-fit indices antara model penelitian dengan model alternatif dapat dilihat pada Tabel 4.

Tabel 4

Goodness of Fit Indices Model Penelitian dan Model Alternatif

\begin{tabular}{lccc}
\hline \multicolumn{1}{c}{ Gooness of fit indices } & Nilai Kritis & $\begin{array}{c}\text { Model } \\
\text { Penelitian }\end{array}$ & $\begin{array}{c}\text { Model } \\
\text { Alternatif }\end{array}$ \\
\hline X2 - Chi-Square & & 36,895 & 18,427 \\
Derajat bebas, df & & 4 & 3 \\
X $^{2}$ - Significant Probability & $>=0,05$ & 0,000 & 0,000 \\
Relative X2 (Cmin/DF) & $<=2,00$ & 9,224 & 6,142 \\
GFI & $>=0,90$ & 0,930 & 0,962 \\
AGFI & $>=0,90$ & 0,739 & 0,808 \\
TLI & $>=0,95$ & 0,505 & 0,691 \\
CFI & $>=0,94$ & 0,802 & 0,907 \\
RMSEA & $<=0,08$ & 0,215 & 0,170 \\
& & & \\
\hline
\end{tabular}

Sumber: Data primer diolah 
Pada tabel 4. terlihat bahwa model alternatif memiliki tingkat kesesuaian yang lebih baik dibandingkan model penelitian yang ditunjukkan oleh nilai-nilai indeks yang lebih mendekati nilai kritis. Model alternatif memiliki $X^{2}$ - Chi-Square 18,427; df 3; Relative $X^{2}$ (Cmin/DF) 6,142 dan RMSEA 0,170 lebih kecil dari model penelitian 36,895; 4; 9,224 dan 0,215. Model alternatif memiliki GFI 0,962; AGFI 0,808; TLI 0,691 dan CFI 0,907 lebih besar dari model penelitian 0,$930 ; 0,739 ; 0,505$ dan 0,802 . Chi-square dan degree of freedom model penelitian (chi-square $36,895 \mathrm{df} 4$ ) dan model alternatif (chi-square 18,427 df 3) menunjukkan perbedaan yang signifikan pada $p=0,001$. Perbedaan yang signifikan tersebut memungkinkan model alternatif digunakan untuk menggantikan model penelitian.

\subsection{Pembahasan}

Tujuan penelitian ini menguji model hubungan LMX dengan kepuasan kerja dan komitmen organisasional yang dimediasi oleh keadilan organisasional. Hasil penelitian menunjukkan bahwa selain hubungan parsial antar variabel penelitian, kita juga dapat melihat hubungan secara simultan variabel-variabel penelitian. Secara umum hampir semua hipotesis yang diajukan didukung karena hanya satu hipotesis yang tidak didukung.

Pada penelitian ini ditemukan bahwa LMX merupakan anteseden keadilan organisasional yang mana kualitas LMX akan mempengaruhi persepsi bawahan terhadap keadilan di dalam organisasi. Semakin tinggi kualitas LMX semakin tinggi pula persepsi bawahan terhadap keadilan di tempat kerjanya. Hasil tersebut mendukung penelitian Pillai et al. (1999). Anggota mempersepsikan apa yang diperoleh baik reward maupun penghargaan yang lain merupakan konsekuensi yang diterima sesuai dengan apa yang telah dilakukannya baik dalam tugas formal maupun perilaku ekstra, sehingga mereka melihat distribusi outcome tidak didasarkan pada equality tapi equity yaitu membandingkan input dan outcome. Anggota juga akan mempersepsikan bahwa prosedur penetapan outcome adalah adil karena adanya hubungan yang baik antara mereka dengan atasannya dan adanya kesempatan bagi karyawan untuk berkontribusi pada prosedur penetapan tersebut. Namun hasil penelitian mengindikasikan bahwa pengaruh LMX terhadap persepsi keadilan prosedural karyawan lebih besar dibandingkan pengaruh terhadap keadilan distributif karyawan. Hal tersebut dapat dilihat dari koefisien jalur LMX ke KP lebih besar daripada LMX ke KD. Ini berarti karyawan akan lebih memandang distribusi outcome adil apabila mereka percaya bahwa prosedur penetapan distribusi tersebut adil.

Hasil penelitian menunjukkan persepsi karyawan pada keadilan distribusi outcome berpengaruh positif signifikan terhadap kepuasaan kerja. Karyawan yang menganggap bahwa apa yang mereka dapatkan baik itu reward atau penghargaan lainnya adil maka mereka akan merasa nyaman dengan hal-hal yang berkaitan dengan pekerjaan. Hampir semua sampel penelitian ini memiliki latar belakang pendidikan yang sesuai dengan kompetensi kerja mereka, maka dari semua unsur kepuasan kerja yaitu kepuasan kerja yang berkaitan dengan pekerjaan itu sendiri, upah, kesempatan promosi, supervisi, rekan kerja, kelompok kerja dan kondisi kerja, hanya kepuasan kerja yang mengarah pada pekerjaan itu sendiri merupakan faktor yang dapat menjelaskan kepuasan kerja mereka. Namun secara umum dapat dikatakan bahwa hasil ini mendukung penelitian sebelumnya yaitu Manogran et al. (1994), Pillai et al. (1999), dan Colquitt et al. (2001) dan memperkuat adanya hubungan antara keadilan distributif dengan kepuasan kerja.

Komitmen organisasional pada penelitian ini didasarkan pada pengukuran komitmen afektif yang artinya karyawan mempunyai keinginan untuk tetap tinggal di dalam organisasi apabila tujuan organisasi sama dengan tujuan mereka. Persepsi bahwa prosedur distribusi outcome adalah adil mengisyaratkan bahwa apa yang menjadi tujuan individu telah diakomodir oleh organisasi. Apabila karyawan merasa tidak sesuai dengan tujuan organisasi besar kemungkinannya untuk meninggalkan organisasi. Pengaruh persepsi karyawan terhadap keadilan prosedur distribusi outcome menjadi penting untuk menghindari perilaku menarik diri yang 
diakibatkan oleh karyawan dengan komitmen organisasional yang rendah. Hasil penelitian ini mendukung penelitian Colquitt et al. (2001) bahwa semakin adil karyawan mempersepsikan keadilan prosedural maka semakin tinggi komitmen organisasionalnya

Selain berpengaruh langsung signifikan pada keadilan organisasional, LMX juga berpengaruh secara langsung signifikan terhadap kepuasan kerja namun tidak pada komitmen organisasional. Pada penelitian ini kualitas hubungan pemimpin bawahan yang semakin tinggi tidak berpengaruh langsung pada komitmen organisasional. Hal tersebut berbeda dengan penelitian Manogran et al. (1994) dan Erdogan et al. (2002) yang mana faktor hubungan yang adil antara bawahan dengan pemimpin berpengaruh pada hasrat karyawan tetap tinggal di organisasi. Namun pada penelitian ini kualitas hubungan antara pemimpin dan bawahan tidak berpengaruh pada komitmen organisasional karyawan, jadi apabila karyawan menganggap tidak terdapat kesesuaian lagi antara tujuan individu dengan organisasi maka mereka akan memutuskan untuk meninggalkan organisasi.

Keadilan organisasional memediasi secara signifikan hubungan LMX dengan kepuasan kerja dan komitmen organisasional. Hasil ini mendukung penelitian Pillai et al. (1999) ditambah dengan dimasukkannya komitmen organisasional sebagai salah satu variabel outcome. Kualitas hubungan pemimpin-anggota akan mempengaruhi persepsi anggota terhadap keadilan organisasional dan selanjutnya akan mempengaruhi kepuasan kerja dan komitmen organisasional mereka. Hasil tersebut mengindikasikan betapa pentingnya faktor keadilan organisasional pada terbentuknya sikap karyawan yang mengarah pada efektivitas organisasi.

Penelitian ini tidak mungkin tanpa suatu keterbatasan. Pertama, penelitian ini hanya menggunakan instrumen survai tunggal. Meskipun menurut Dorfman (1996 dalam Pillai et al., 1999) pada penelitian sikap dan keperilakuan pengukuran dengan instrumen survai tunggal merepresentasikan respon individual yang unik, namun pada penelitian LMX selanjutnya diharapkan menggunakan instrumen ganda sehingga dapat diukur baik dari persepsi bawahan maupun atasan. Kedua, penelitian ini menggunakan instrumen LMX yang bersifat unidimensional yang dikembangkan Scandura dan Graen (1984). Pada penelitian selanjutnya diharapkan menggunakan LMX yang bersifat mutidimensional (LMX-MDM) sehingga riset mengenai LMX dapat lebih berkembang. Ketiga, keterbatasan penelitian yang berhubungan dengan validitas eksternal. Karena sampel penelitian hanya mewakili beberapa perusahaan swasta di industri perminyakan, maka hasil penelitian in tidak layak untuk digeneralisir pada tipe organisasi publik atau swasta lainnya. Penelitian selanjutnya diharapkan dapat dilakukan pada lingkup yang lebih luas sehingga hasilnya dapat lebih umum.

\section{DAFTAR PUSTAKA}

Andrews, M.C., dan Kacmar, K.M., (2001), "Discriminating among Organizational Politicts, Justice, and Support", Journal of Organizational Behavior, 22: 347-366.

Bauer, T.N., dan Green, S.G., (1996), "Development of Leader-Member Exchange: A Longitudinal Test", Academy of Management Journal, 39: 1538-1568.

Clugston, M., (2000), "The Mediating Effects of Multidimensional Commitment on Job Satisfaction and Intent to Leave", Journal of Organizational Behavior, 27: 477-486.

Colquitt, J.A., (2001), "On the Dimensionality of Organizational Justice : A construct Validation of a Measure", Journal of Applied Psychology, 86: 386-400.

Dienesch, R.M., dan Liden, R.C., (1986), "Leader-Member Exchange Model of Leadership: A Critique and Further Development", Academy of Management Review, 11: 616-634. 
Dionne, L., (2000), "Leader-Member Exchange (LMX) Level of Negotiating Latitude and Job Satisfaction", Unpublished.

Dunham, B.R., Grube, J.A., dan Castaneda, M.B., (1994), "Organizational Commitment: The Utility of an Integrative Definition", Journal of Applied Psychology, 79: 370-380.

Erdogan, B., Kraimer, dan M.L., Liden, R.C., (2002), "Person-Organization Fit and Work Attitudes: The Moderating Role of Leader-Member Exchange", Academy of Management Proceedings.

Greenberg, J., dan Baron, R.A., (2003), Behavior in Organizations, Eight Edition, Prentice Hall.

Hair, J.F.Jr, Anderson, R.E., Tatham, R.L., dan Black, W.C., (1998), Multivariate Data Analysis, New Jersey: Prentice Hall.

Lam, K.S.S., Schaubroeck, J., dan Aryee, S., (2002), "Relationship between Organizational Justice and Employee Work Outcomes: a Cross-national Study", Journal of Organizational Behavior, 23: 1-8.

Lee, H.R., (2000), "An Empirical Study of Organizational Justice as a Mediator of the Relationship among Leader-Member Exchange and Job Satisfaction, Organizational Commitment, and Turnover Intentions in the Lodging Industry", Unpublished Dissertation.

Liden, R.C., Wayne, S.J., dan Stilwell, D., (1993), "A Longitudinal Study on the Early Development of Leader-Member Exchanges", Journal of Applied Psychology, 78: 662-674.

Lum, L., Kervin, J., Clark, K., Reid, F, dan Sirola, W., (1998), "Explaining Nursing Turnover Intention: Job Satisfaction, Pay Satisfaction, or Organizational Commitment", Journal of Organizational Behavior, 19: 305-320.

Manogran, P., Staufer, J., dan Conlon, E.J., (1994), "Leader-Member Exchange as A Key Mediating Variable Between Employees Perceptions of Fairness and Organizational Citizenship Behavior", National Academy of Management Meeting Proceeding, Dallas, TX.

Pillai, R., Scandura, T.A., dan Williams, E.A., (1999), "Leadership and Organizational Justice : Similarities and Differences across Cultures", Journal of International Business Studies, 30: 763-779.

Scandura, T.A., (1999), "Rethinking Leader-Member Exchange: an Organizational Justice Perspective", Leadership Quarterly, 10: 25-41.

Scandura, T.A., dan Graen, G.B., (1984), "Moderating Effects of Initial Leader-Member Exchange Staatus on the Efffects of a Leadership Intervention", Journal of Applied Psychology, 69: 428-436.

Sherony, K.M., dan Green, S.G., (2002), "Coworker Exchange: Relationships Between Coworkers, Leader-Member Exchange, and Work Attitudes", Journal of Applied Psychology, 87: 542548. 
KINERJA, Volume 9, No.2, Th. 2005: Hal. 162-172

Testa, M.R., (2001), "Organizational Commitment, Job Satisfaction, and Effort in The Service Environment", Journal of Psychology, 135.

Wayne, S.J., Shore, L.M., Bommer, W.H., dan Tetrick, L.E., (2002), "The Role of Fair Treatment and Rewards in Perceptions of Organizational Support and Leader-Member Exchange", Journal of Applied Psychology, 87: 590-598. 